\title{
Titanium foam made with saccharose as a space holder
}

\author{
J. Jakubowicz $\cdot$ G. Adamek $\cdot$ M. Dewidar
}

Published online: 2 April 2013

(c) The Author(s) 2013. This article is published with open access at Springerlink.com

\begin{abstract}
In this work we show a very promising method of titanium foam preparation with saccharose crystals (table sugar) as a space holder particles. The mixture of $\mathrm{Ti}$ and sugar particles was compacted to form a green compacts. In the next step the saccharose crystals were dissolved in the water, leaving open spaces surrounded by metallic scaffold. The sintering of the scaffold leads to foam with typical morphology and porosity. We found that $1: 1 \mathrm{Ti} /$ sugar ratio leads to porosities of about $72 \%$ with pore diameter of about $0.8-1.0 \mathrm{~mm}$, when we used $0.8-1.0 \mathrm{~mm}$ diameter sugar crystals. The foams morphology was investigated by SEM, porosity and internal structure was investigated using computed tomography and the structure was shown using XRD. The foam morphology pointed theirs potential applications in medical as well as catalyst devices.
\end{abstract}

Keywords Metal foam - Biomaterials .

Saccharose space holder

\section{Introduction}

Metal foams are a relatively old materials having more than half century of history [1], but theirs applications are still promising and perspective. The metal foams can be

J. Jakubowicz $(\bowtie)$ · G. Adamek

Institute of Materials Science and Engineering,

Poznan University of Technology,

M. Sklodowska-Curie 5 Sq., 60-965 Poznan, Poland

e-mail: jaroslaw.jakubowicz@ put.poznan.pl

M. Dewidar

Department of Materials and Mechanical Design,

Faculty of Engineering Energy, Aswan University,

Aswan, Egypt used for example in implants, filters, energy absorbers [2]. The common technique of metal foam preparation is sintering with a space holder. The space holder particles are mixed with metallic powder, then compacted and finally removed during or before sintering. A different space holder materials can be used, for example: sodium chloride, sodium fluoride, carbamide, ammonium hydrogen carbonate, titanium dihydride, magnesium and even tapioca [3-9]. All above mentioned space holder materials are useful in $\mathrm{Ti}$ or Ti-alloy foams preparation. The space holders can be removed by temperature (evaporation) or by the solvent (dissolution). In many cases the process of dissolution is time consuming [6] and ineffective.

The porous foams have unique properties with very low Young's modulus (E). For hard tissue implant applications the $\mathrm{E}$ has a key factor. The bone has $\mathrm{E}$ in the range 10-30 GPa, whereas best bulk metallic implants has E about $110 \mathrm{GPa}$ [10]. This mismatch in $\mathrm{E}$ value lead to stress-shielding and can be avoided by pores introduction into the material. Hence the porosity is the most important factor in E tailoring and is expressed by the following Eq. (1) $[8,11]$ :

$\frac{E_{p}}{E_{s}}=k(1-P)^{2}$

where: $k$-constant; $E_{p}$ and $E_{s}$-Young's modulus for porous and solid $\mathrm{Ti}$, respectively; $\mathrm{P}$ - porosity of porous $\mathrm{Ti}$.

Beside the Young modulus decreasing, the porous foams promotes bone ingrowth into the pores, providing strong fixation with bone. Another positive point of the metallic foam is its low density and weight, which improve a patient comfort. The main drawback of the metallic foam is poor bending stress [12].

In this work we proposed a new space holder material, which is commonly accessible and easy for application. 
The saccharose crystals (also known as sucrose or table sugar) with chemical formula $\mathrm{C}_{12} \mathrm{H}_{22} \mathrm{O}_{11}$, obtained from sugar beet. It is a nonreducing disaccharide composed of glucose and fructose linked via their anomeric carbons.

We shows that the simple water dissolution of sugar crystals leave the open spaces comparable to commonly known metal foams.

\section{Experimental data}

Metal foams were prepared using mixture of spherical $\mathrm{Ti}$ particles as a metal scaffold component, with particles size less than $50 \mu \mathrm{m}$ (supplied by Se-Jong Materials Ltd., South Korea, with purity of $99.5 \%$ ) and cubical saccharose crystals (table sugar) with size of about $0.8-1 \mathrm{~mm}$ (supplied by Pfeifer \& Langen Poland, with purity of $99.8 \%$ ). The procedure [13] of foams preparation is shown on Fig. 1. The Ti/ saccharose weight ratio was $1: 1$. The powders were mixed in Spex 8000 mixer mill for $30 \mathrm{~s}$. For the powders binding a 3 droplets of ethanol per $10 \mathrm{~g}$ of powders mixture were add. The mixture was then compacted using uniaxial pressing at about $500 \mathrm{MPa}$. The final green compact had $8 \mathrm{~mm}$ diameter and high. After that, the compact was placed into distilled water with temperature $20-80{ }^{\circ} \mathrm{C}$. The magnetic stirring (10-20 rpm) supporting sugar dissolution. The time of space holder removing was $2-6 \mathrm{~h}$. In the next step, the compacts were dried at about $80^{\circ} \mathrm{C}$ for up to $1 \mathrm{~h}$. For the sintering the compacts were heated for $1 \mathrm{~h}$ from room temperature (RT) up to a $1,250{ }^{\circ} \mathrm{C}$ kept for $1 \mathrm{~h}$. The sintering was done in vacuum $\left(10^{-2} \mathrm{mbar}\right)$ in ceramic tube furnace (Nabertherm). In the last stage the metal foam was cooled down to RT for the $1 \mathrm{~h}$.

The porosity was estimated using a computed tomography. The Vega Tescan SEM and Carl Zeiss Metrotom

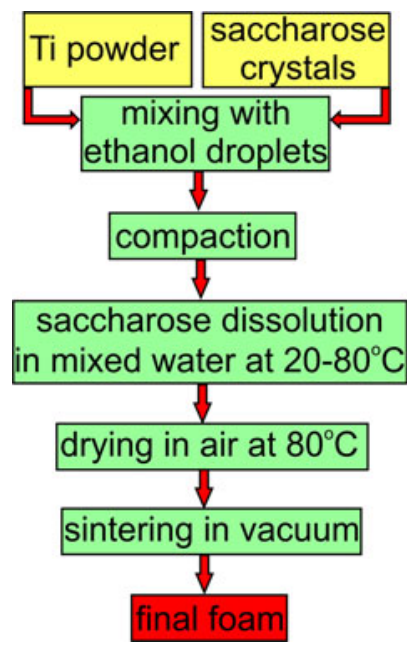

Fig. 1 Scheme of Ti foam preparation with saccharose as a space holder
800 computed tomography (CT) were applied for the foams pore and scaffold morphology investigation. The structure was identified by Panalytical Empyrean XRD with $\mathrm{Cu} \mathrm{K} \alpha$ radiation.

\section{Results and discussion}

The sugar crystals, applied as the space holder particles, well defining the pore size during compacting of the $\mathrm{Ti} /$ sugar mixture. The applied mixing procedure gives a uniform sugar particles distribution, without deterioration and reducing the size of sugar particles. The small amount of ethanol providing respective binding of the powders during compacting. It was a relatively small amount of liquid, which no lead to sugar crystal dissolution. The compacts have good mechanical strength, respective for making the next consolidation stage. During the space holder removing, done in mixed water, the sugar crystals were dissolved leading to open spaces surrounded by the $\mathrm{Ti}$ scaffold. The strength of the compact was enough to keep mechanical integration during holding by tweezers, drying and placing into the furnace for sintering. The rising water temperature, from 20 to $80^{\circ} \mathrm{C}$, supporting and shortening sugar dissolution.

During sintering, the mechanical integrity of the sinters increases because high temperature diffusion leading to $\mathrm{Ti}$ particles bonding. The Fig. 2 shows computed tomography (left row) and SEM (right row) pictures of the foams. The sample was characterized in different directions and planes, using CT technique. The cross sections of the sample in three directions were recorded with step of $0.01 \mathrm{~mm}$. From the hundreds of cross sections a few representative are shown in this work. The Fig. 2a shows top view SEM picture and respective cross section obtained with using CT technique. Figure $2 \mathrm{~b}$ shows side view SEM picture and respective side cross section obtained with using CT technique. Finally Fig. 2c shows top-side angle view SEM picture and respective cross section obtained with using CT technique. The symmetrical and properly distributed pores are well visible in the foams. The shape of the pores is related to shape of the initial symmetrical sugar crystals. The pores are rectangular and the pore walls are straight. The made foams shows $72 \%$ porosity. The two types of pores are formed in the foams, which were detected by both CT and SEM (Fig. 3a, b respectively). Larger macropores were defined by space holder sugar particles (0.8-1.0 mm diameter) and smaller ones formed between pressed and sintered Ti particles ( $2-50 \mu \mathrm{m}$ diameter). The total volume of the sample was about $320 \mathrm{~mm}^{3}$, whereas volume of the material and closed pores were $91.18 \mathrm{~mm}^{3}$ and $0.447 \mathrm{~mm}^{3}$, respectively. According to CT measurements, the pores formed in the foam are mostly 
Fig. 2 CT cross sections (left row) and SEM pictures (right row) of the Ti foam made with saccharose as a space holder; top view (a), side view (b) and angle top-side view (c)
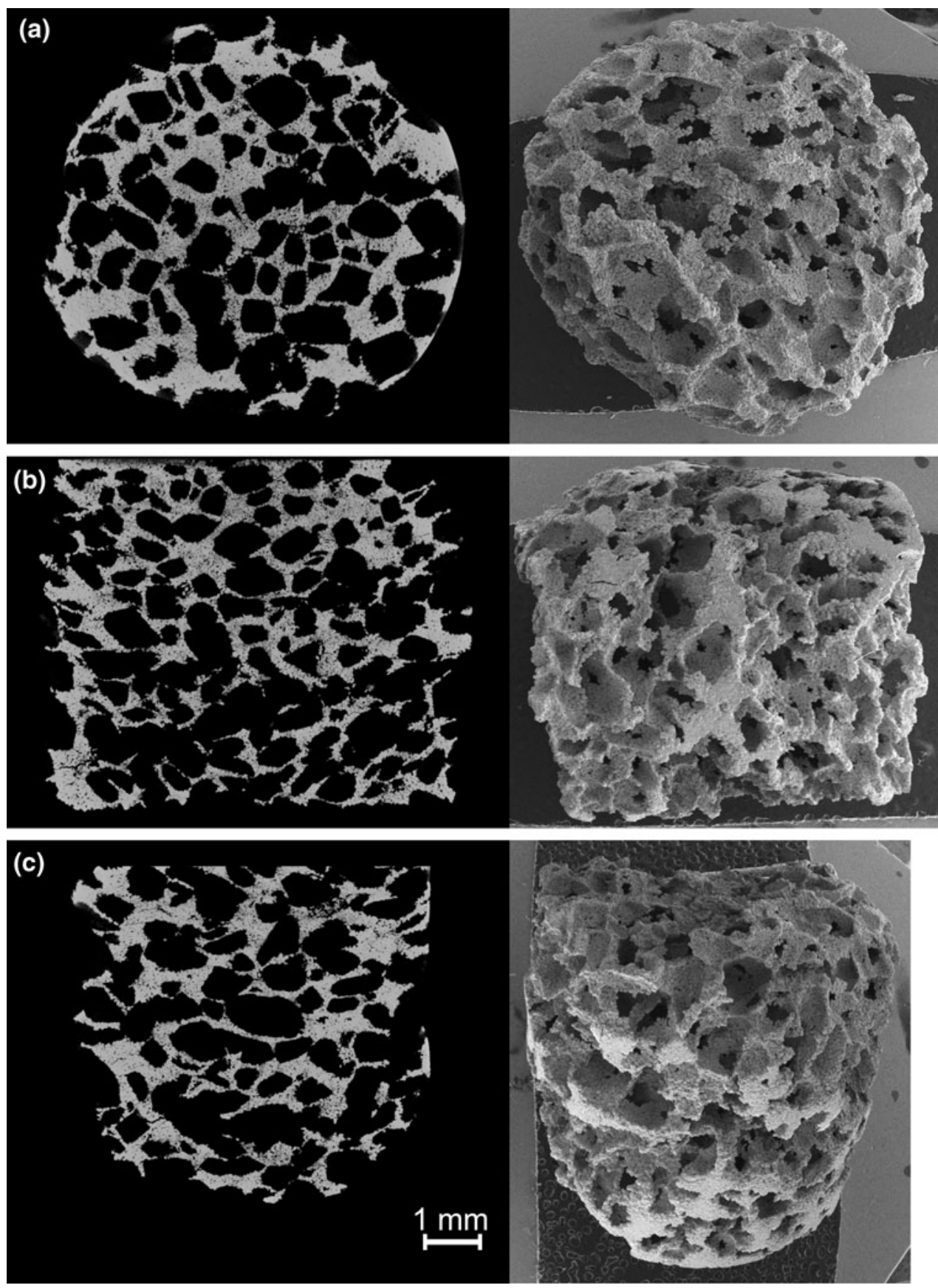

interconnected, with total volume of about $228.37 \mathrm{~mm}^{3}$. No single closed pores with volume larger than $0.02 \mathrm{~mm}^{3}$ were observed. The sugar crystals were totally removed during dissolution in water, giving a well defined pores.

The XRD investigations shows formation of partially oxidized foams (Fig. 4c) with traces of saccharose. A sugar and Ti XRD spectra ( $a$ and $b$, respectively) are shown for comparison. The $\mathrm{Ti}$ is sensitive for oxidation, so on the initial Ti powders surface (even kept in protective atmosphere) the titanium oxide were detected. The next processing stages (pressing in air, dissolution in water, sintering in argon) lead to Ti oxide formation, too. Even the sugar traces in the foam were detected, its presence is not charged a risk, because saccharose is not classifiable as a human carcinogen [14]. So, taking into account foams morphology, the biomedical applications of these foams seems to be very promising. The observed foam morphology is typical and well comparable to those made with ammonium hydrogen carbonate [12], carbamide [5] or polymer particles [15].

The most comparable food space holder is sodium chloride [7]. Unfortunately it is not as safe for human as 
Fig. 3 CT cross section (a) and SEM picture (b) of the Ti foam made with saccharose as a space holder, showing two types of pores
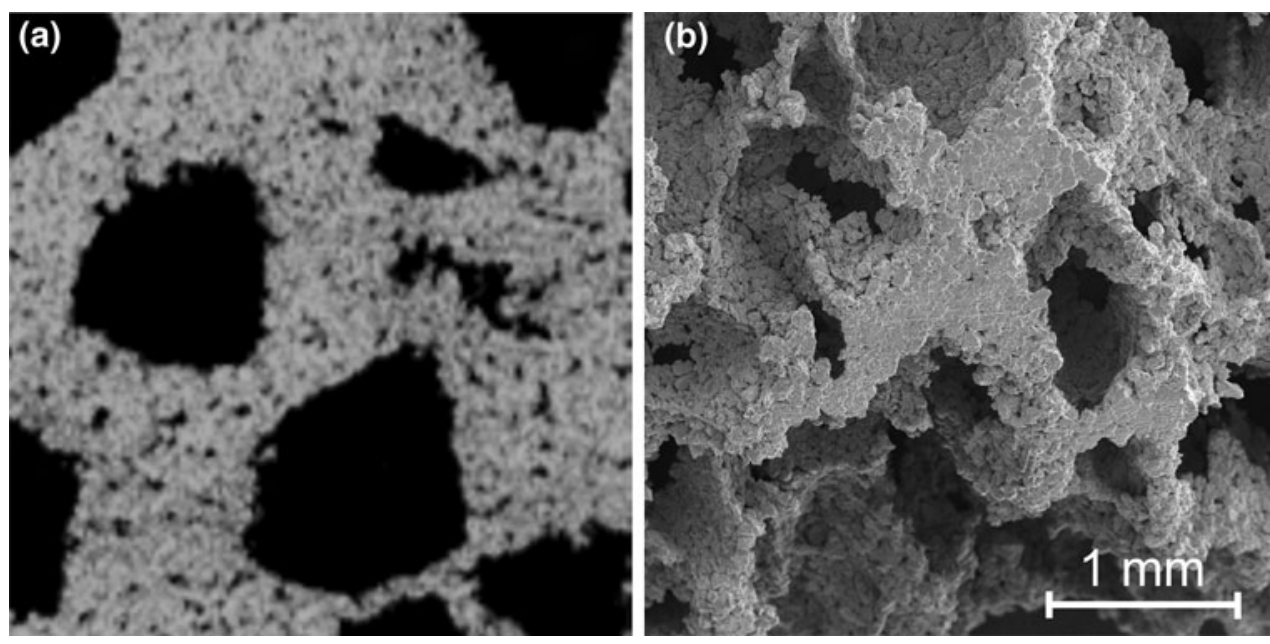

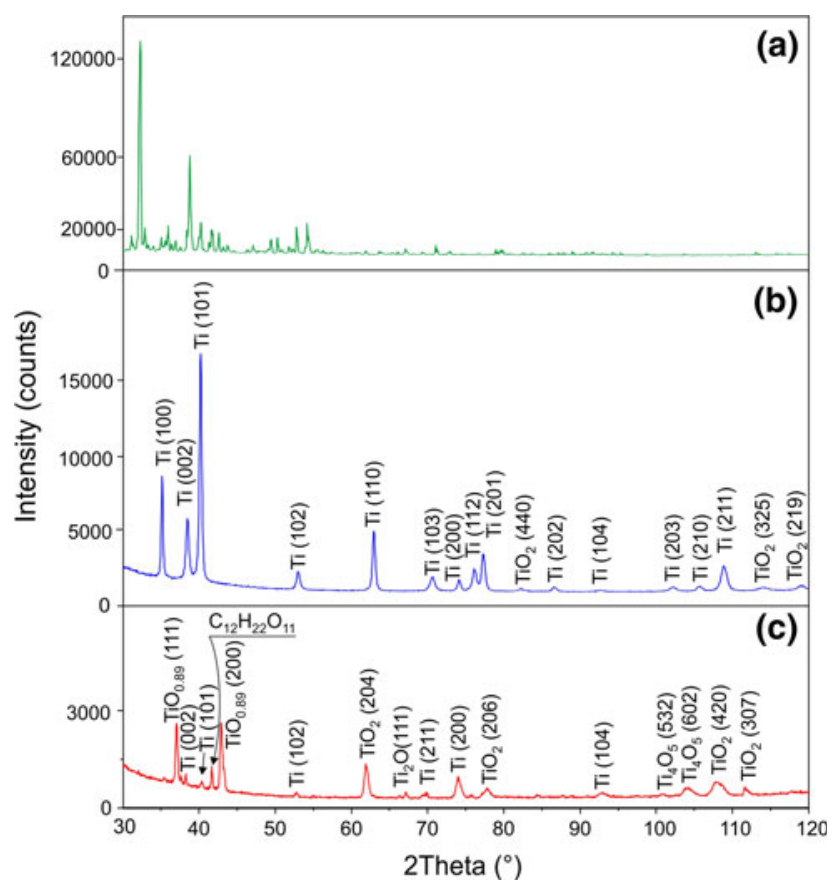

Fig. 4 XRD spectra of the table sugar crystals (a), Ti powders (b) and final Ti foam $(c)$

saccharose and may induce a corrosion of the Ti scaffold due to presence of chloride. Ye and Dunand [16] investigated open-celled titanium foams fabricated by vacuum hot pressing of a blend of $\mathrm{Ti}$ and $\mathrm{NaCl}$ powders at $780{ }^{\circ} \mathrm{C}$ followed by $\mathrm{NaCl}$ removal in water. So in this case $\mathrm{NaCl}$ dissolution in water was take place after densification. It is a main drawback consolidation of the space holder together with a metallic component, because at elevated temperature a surface reactions and diffusion of $\mathrm{Na}$ or $\mathrm{Cl}$ is possible into the $\mathrm{Ti}$ scaffold and hence corrosion resistance and mechanical properties deterioration is possible. In our case, dissolution of saccharose space holder was made before sintering and high temperature reaction of saccharose with Ti was eliminated.

\section{Conclusion}

In this work we shows a simple and cheap method for metal foam preparation with using a commonly available food material. The titanium foam with high porosity and large pore size was successfully prepared using the saccharose crystals as the space holder particles. The method of foam formation can be applied in any laboratory with basic equipment for powder metallurgy. The possible application in medical equipment depends on the mechanical strength of the foam and in vitro as well as in vivo behavior. The other technical applications are possible, too. The process need further optimization, but the above results clearly shows a great potential of saccharose (table sugar) applications in metallic foam formation. The computed tomography is a powerful tool for internal structure analysis. The made foams shows $72 \%$ porosity and the pores with size of $0.8-1 \mathrm{~mm}$ are mainly interconnected. As we shown, the saccharose as a space holder can be easily removed leaving a porous scaffold.

Acknowledgments The financial support of the Polish National Centre for Science is gratefully acknowledged.

Open Access This article is distributed under the terms of the Creative Commons Attribution License which permits any use, distribution, and reproduction in any medium, provided the original author(s) and the source are credited.

\section{References}

1. B. Sosnik, Process for making foamlike mass of metal, U.S. Patent 2,434,775, 1948 
2. M.F. Ashby, A.G. Evans, N.A. Fleck, L.J. Gibson, J.W. Hutchinson, N.H.G. Wadley, Metal foams: a design guide (Butterworth-Heinemann, Woburn, 2000)

3. Y.Y. Zhao, D.X. Sun, A novel sintering-dissolution process for manufacturing Al foams. Scr. Mater. 44, 105 (2001)

4. C.E. Wen, M. Mabuchi, M. Yamada, K. Shimojima, Y. Chino, $\mathrm{T}$. Asahina, Processing of biomedical porous foam of $\mathrm{Ti}$ and $\mathrm{Mg}$. Scr. Mater. 45, 1147 (2001)

5. N. Wenjuan, B. Chenguang, Q. Guibao, W. Qiang, Processing and properties of porous titanium using space holder technique. Mat. Sci. Eng. A506, 148 (2009)

6. A. Bansiddhi, D.C. Dunand, Shape memory NiTi foams produced by solid state replication with NaF. Intermetalics 15, 1612 (2007)

7. A. Bansiddhi, D.C. Dunand, Shape memory NiTi foams produced by replication of $\mathrm{NaCl}$ space holders. Acta Biomat. 4, 1996 (2008)

8. Y.W. Gu, M.S. Yong, B.Y. Tay, C.S. Lim, Synthesis and bioactivity of porous $\mathrm{Ti}$ alloy prepared by foaming with $\mathrm{TiH}_{2}$. Mater. Sci. Eng. C. 29, 1515 (2009)

9. A. Mansourighasri, N. Muhamad, A.B. Sulong, Processing titanium foams using tapioca starch as a space holder. J. Mater. Proc. Techn. 212, 83 (2012)
10. I.-H. Oh, N. Nomura, N. Masahashi, S. Hanada, Mechanical properties of porous titanium compacts prepared by powder sintering. Scr. Mater. 49, 1197 (2003)

11. Y. Mizuno, F.K. King, Y. Yamauchi, T. Homma, A. Tanaka, Y. Takakuwa, T.J. Momose, Temperature dependence of oxide decomposition on titanium surfaces in UHV. Vac. Sci. Technol. A20, 1716 (2002)

12. X. Wang, Y. Li, J. Xiong, P.D. Hodgson, C. Wen, Porous TiNbZr alloy scaffolds for biomedical applications. Acta Biomater. 5, 3616 (2009)

13. G. Adamek, M. Dewidar, J. Jakubowicz, Method for porous sinter formation, Polish Patent P.399743, 2 July 2012

14. Hazardous Substances Data Bank (HSDB), a database of the National Library of Medicine's TOXNET system. http://toxnet. nlm.nih.gov on Oct 122012

15. I.-H. Kim, W. Lee, S.-H. Ko, J.M. Jang, Compression temperature and binder ratio on a process for fabrication of open-celled porous Ti. Mater. Res. Bull. 45, 355 (2010)

16. B. Ye, D.C. Dunand, Titanium foams produced by solid-state replication of $\mathrm{NaCl}$ powders. Mater. Sci. Eng. A. 528, 691 (2010) 